\title{
CULTIVO DO TOMATEIRO EM SUBSTRATOS ORGÂNICOS SOB APLICAÇÃO FOLIAR DE SILICATO DE POTÁSSIO EM AMBIENTE PROTEGIDO ${ }^{1}$
}

\author{
Cultivation of tomato in organic substrates under leaf spraying of \\ potassium silicate in protected environment ${ }^{1}$ \\ Eduardo Bucsan Emrich², Rovilson José de Souza ${ }^{3}$, Antonio Anicete de Lima \\ Felipe Campos Figueiredo ${ }^{5}$, Douglas Ramos Guelfi Silva ${ }^{6}$
}

\begin{abstract}
RESUMO
Conduziu-se este trabalho, com o objetivo de avaliar o efeito da aplicação, via foliar, de diferentes doses de silicato de potássio, sob os teores de clorofila $a, b$ e total em folhas de tomateiro cultivados em dois substratos e a influência desses fatores na produtividade da cultura sob ambiente protegido. O delineamento experimental foi de blocos ao acaso, em esquema fatorial 2 x 4, com quatro repetições. Foram utilizados os substratos fibra de coco (S1) e fibra de coco acrescido de casca de café carbonizada (S2). As doses de silicato de potássio foram $0 ; 0,1 ; 0,2$ e $0,4 \%$ do produto Sili- $\mathrm{K}^{\circledast}$. As doses do produto foram aplicadas semanalmente nas folhas das plantas, durante o ciclo da cultura. Antes da primeira colheita de frutos, quantificaram-se os teores de clorofila $a, b$ e total, que apresentaram diferenças significativas apenas para S1. O aumento das doses de silicato de potássio aplicadas estimulou, de forma linear, a concentração de clorofila $a, b$ e total em folhas de tomateiros. A massa média de frutos com diâmetro de 60 a $65 \mathrm{~mm}$ cultivados em S2 foi influenciada pelas diferentes doses de silicato de potássio. A dose $0,2 \%$ foi significativamente superior às concentrações testadas.
\end{abstract}

Termos para indexação: Fibra de coco, casca de café carbonizada, cultivo em vasos, clorofila.

\begin{abstract}
This study was to evaluate the effect of leaf application of different doses of potassium silicate, on the levels of chlorophyll $a, b$ and total in leaves of tomato cultivated in two substrates as well as the influence of these factors on crop yield under protected environment. The used experimental design was randomized blocks with four replicates. A factorial scheme $2 \times 4$ was used. The substrates were coconut fiber (S1) and coconut fibercombined with carbonized coffee husk (S2). The Used doses of potassium silicate were $0,0.1,0.2$ and $0.4 \%$ of Sili- $\mathrm{K}^{\circledR}$. These doses were sprayed weekly on the leaves during the dant cycle. Before the first harvest, chlorophylls $a, b$ and total. that present significative differences only for $\mathrm{S} 1$ were quantified. The increase of potassium silicate doses stimulated the concentration of chlorophyll $a, b$ and total chlorophyll. The average mass of fruits with 60 to $65 \mathrm{~mm}$, diameter cultivated in S2 was influenced by the different doses of potassium silicate. The dose of $0.2 \%$ was the best concentration.
\end{abstract}

Index terms: Coconut fiber, carbonized coffee husk, culture in vases, chlorophyll.

(Recebido em 22 de outubro de 2009 e aprovado em 21 de maio de 2010)

\section{INTRODUÇÃO}

O tomateiro (Solanum lycopersicum L.) é uma solanácea originária da região andina (Rick, 1982). Configura-se como uma das hortaliças mais cultivadas no mundo e, por sua boa aparência, sabor, aroma, textura e valor nutricional, é também uma das mais consumidas (Schuch et al., 1991).

A cultura do tomateiro é amplamente difundida no Brasil, mostrando-se presente em quase todas as regiões e climas. Porém, é também acometida por diversos tipos de doenças. Os métodos de controle dessas doenças vêm passando por alterações em virtude da adoção de práticas preventivas baseadas no manejo correto de fertilizantes e na nutrição das plantas, fatores esses que podem ser manipulados com relativa facilidade.

O silício ( $\mathrm{Si}$ ) é considerado nutriente essencial para as plantas por alguns autores (Epstein \& Bloom, 2006) e apenas benéfico por outros (Marschner, 1995; Korndorfer, 2006). É encontrado nos tecidos de todas as plantas, concentrando-se, principalmente, nas folhas e caules. De acordo com Epstein (1994) e Marschner (1995), o silício pode estimular o crescimento e a produção vegetal por meio de várias ações indiretas, como a diminuição do autossombreamento, o decréscimo na suscetibilidade ao acamamento, a maior rigidez estrutural dos tecidos, a proteção contra estresses abióticos, como a redução da

\footnotetext{
Parte da dissertação de Mestrado em Fitotecnia, apresentada pelo primeiro autor à Universidade Federal de Lavras/UFLA - Lavras, MG

2Universidade Federal de Lavras/UFLA - Cx. P. 3037 - 37200-000 - Lavras, MG - bucsan_emrich@yahoo.com.br

${ }^{3}$ Universidade federal de Lavras/UFLA - Departamento de Agricultura/DAG - Lavras, MG

${ }^{4}$ Universidade Federal de Lavas/UFLA - Lavras, MG

Instituto Federal de Educação, Ciência e Tecnologia de Muzambinho - Muzambinho, MG

Universidade Federal de Lavras/UFLA - Departamento de Ciência do Solo/DCS - Lavras, MG
} 
toxidez por $\mathrm{Al}, \mathrm{Mn}, \mathrm{Fe}$ e $\mathrm{Na}$, a diminuição na incidência de patógenos e o aumento na proteção contra herbívoros, incluindo insetos fitófagos. A aplicação foliar de fontes de silício líquido solúvel tem sido foco de várias pesquisas pela sua eficácia, praticidade, uso de doses menores e também como adaptável aos pulverizadores normalmente utilizados por muitos produtores (Figueiredo et al., 2010). Para o cultivo em recipientes, o substrato deve apresentar condições adequadas à germinação e desenvolvimento do sistema radicular da mesma (Araújo et al., 2010).

Dessa maneira, faz-se necessário o conhecimento das propriedades químicas e físicas dos substratos utilizados e a melhor maneira de se fornecer nutrientes às culturas.

Além disso, outro aspecto importante a ser considerado é que as clorofilas exercem um controle dominante sobre a quantidade de radiação solar absorvida pelas plantas e, por essa via, as suas concentrações foliares guardam uma estreita relação com as taxas fotossintéticas e a produtividade primária das culturas (Streit et al., 2005; Blackburn, 2007).

A determinação dos teores de clorofilas das folhas tem grande relevância porque a atividade fotossintética da planta depende, em parte, da capacidade de folha absorver luz.

Diante disso, conduziu-se este trabalho, com o objetivo de avaliar o efeito da aplicação, via foliar, de diferentes doses de silicato de potássio, sob os teores de clorofila $a, b$ e total em folhas de tomateiro cultivados em dois substratos e a influência desses fatores na produtividade da cultura sob ambiente protegido.

\section{MATERIAL E MÉTODOS}

O experimento, conduzido no período de agosto a dezembro de 2008, em estufa situada no Setor de Olericultura do Departamento de Agricultura da Universidade Federal de Lavras, foi realizado com plantas de tomateiro do híbrido 'Facundo', de hábito de crescimento indeterminado e frutos do grupo salada.

O delineamento experimental adotado foi em blocos casualizados, em esquema fatorial 4 x 2, com quatro repetições. Foram utilizadas 4 doses de silicato de potássio, produto comercial Sili-K ${ }^{\circledR}\left(171 \mathrm{~g} \mathrm{~L}^{-1}\right.$ de Si e $210 \mathrm{~g} \mathrm{~L}^{-1}$ de $\left.\mathrm{K}_{2} \mathrm{O}\right)$, nas concentrações de $0 \%, 0,1 \%, 0,2 \%$ e $0,4 \%$, misturadas com espalhante adesivo (Silwet ${ }^{\circledR}$ ) e utilizados dois tipos de substratos $\left(S_{1}=\right.$ fibra de coco e $S_{2}=$ fibra de coco + casca de café carbonizada na proporção 3:1 em base de volume).

Trinta e cinco dias após a semeadura, 288 mudas, produzidas em bandejas de polietileno expandido, com substrato comercial esterilizado (Plantmax ${ }^{\circledR}$ ), foram transplantadas para sacos plásticos com capacidade de 7 litros. As mudas foram acomodadas em estufa de produção coberta com polietileno de densidade de 150 micras, modelo capela, com $30 \mathrm{~m}$ de comprimento, $10 \mathrm{~m}$ de largura e $1,80 \mathrm{~m}$ de pé direito.

Cada parcela experimental foi representada por nove plantas e as cinco plantas centrais foram consideradas como área útil. Todos os blocos contavam com uma repetição de um tratamento (um tipo de substrato e uma dose de silicato de potássio). Os espaçamentos adotados foram de 1,0 m entre fileiras duplas, $0,8 \mathrm{~m}$ entre fileiras simples e $0,4 \mathrm{~m}$ entre plantas, com densidade de 2,78 plantas $/ \mathrm{m}^{2}$.

As plantas, conduzidas com somente uma haste, foram tutoradas utilizando-se fitilho na vertical, presos a um fio de arame localizado a 2,0 m de altura. Durante todo o ciclo do tomateiro, foram realizadas desbrotas com o intuito de manter uma única haste por planta.

A cada saco plástico foi acoplado um gotejador com múltiplas saídas e vazão média de 1,0 L/hora. O tempo de irrigação foi determinado após drenagem de $30 \%$ do volume total de água, aplicada às sacolas plásticas, e a frequência, ajustada diariamente, de acordo com o estádio de desenvolvimento da cultura e condições climáticas.

O fornecimento de nutrientes foi feito, completamente, via fertirrigação, três vezes por semana, de acordo com o estágio de desenvolvimento da cultura, com vistas a atender suas demandas nutricionais. $\mathrm{O}$ programa de fertilização utilizado foi definido com base em trabalhos anteriores de Castellane \& Araújo (1995). O controle da condutividade elétrica do substrato foi realizado de acordo com a aplicação da técnica do lixiviado ou "Pour through" (Cavins, 2002). Para a manutenção do pH e da condutividade elétrica, foram acrescentados sais sempre que necessário.

As pulverizações foliares com as diferentes doses de silicato de potássio foram executadas, semanalmente, durante todo o ciclo da cultura.

Antes da primeira colheita de frutos, realizou-se a leitura correspondente do teor de clorofila nas folhas que foram feitas com o auxílio do aparelho clorofilômetro marca Minolta (modelo SPAD-502). As determinações foram realizadas por ocasião do florescimento do primeiro cacho de frutos. Escolheram-se cinco folíolos de folhas adultas das cinco plantas centrais de cada tratamento. As leituras com o medidor de clorofila foram feitas em pontos situados na metade a dois terços do comprimento da folha amostrada, a partir da base e a $2 \mathrm{~cm}$ de uma das margens da folha. O aparelho forneceu a leitura dos teores de clorofila $a$, clorofila $b$ e clorofila total. 
Foram realizadas oito colheitas. Em cada uma os frutos de cada tratamento foram separados por tamanhos e pesados.

Os dados obtidos foram submetidos à análise de regressão linear simples.

\section{RESULTADOS E DISCUSSÃO}

As clorofilas são os pigmentos naturais mais abundantes presentes nas plantas e ocorrem nos cloroplastos das folhas e em outros tecidos vegetais. Estudos em uma grande variedade de plantas caracterizaram que os pigmentos clorofilianos são os mesmos. As diferenças aparentes na cor do vegetal são decorrentes da à presença e distribuição variável de outros pigmentos associados, como os carotenóides, os quais sempre acompanham as clorofilas (Elbe, 2000).

As clorofilas $a$ e $b$ são abundantes nas plantas verdes, e as $c$ e $d$ são encontradas em alguns protistas e cianobactérias. Esses pigmentos fotossintetizantes absorvem luz e impulsionam a fotossíntese.

A clorofila $a$ é o pigmento utilizado para realizar a fotoquímica (o primeiro estágio do processo fotossintético), enquanto que os demais pigmentos auxiliam na absorção de luz e na transferência da energia radiante para os centros de reação, sendo assim chamados de pigmentos acessórios. Os principais pigmentos acessórios também incluem outros tipos de clorofilas: Clorofila $b$, presente em vegetais superiores, algas verdes e algumas bactérias; clorofila c, em feófitas e diatomáceas; e clorofila $d$, em algas vermelhas (Taiz \& Zieger, 2004).

$\mathrm{O}$ efeito da aplicação foliar de Si no teor de clorofila foi significativo apenas para o substrato composto integralmente por fibra de coco (S1). Segundo Sánches (1999), a fibra de coco apresenta características relacionadas à retenção e assimilação de água, que a tornam um bom substrato.

Para os dois tipos de clorofila quantificados (clorofila $a$ e clorofila $b$ ), foram observados acréscimos nos teores com o aumento da dose de silicato de potássio utilizada. Concordando com as observações feitas por Gonçalves et al. (2008), que relataram que a deposição e a polimerização do silício na superfície foliar proporcionam melhoria da arquitetura das folhas, redução da perda de água e aumento na eficiência fotossintética, por causa dos incrementos nos teores de clorofila.

Diante disso, verifica-se um acréscimo nos teores de clorofila $a$ com o aumento da dose de silicato de potássio aplicada. Essa variação ocorreu na ordem de $0,68057 \mu \mathrm{g} \mathrm{cm}^{-3}$ a cada $0,1 \%$ de aumento na concentração de silicato de potássio (Figura 1).

Os teores de clorofila $a$ variaram entre 39,87 e $42,59 \mu \mathrm{g} \mathrm{cm}^{-3}$, entre concentrações de 0 e $0,4 \%$ de silicato de potássio, respectivamente. Quando comparados, esses valores mostraram uma diferença de $7 \%$.

Efeito semelhante foi verificado na quantificação de clorofila $b$ (Figura 2). Os valores de clorofila $b$ aumentaram com os acréscimos nas concentrações de silicato de potássio. Para esse tipo de clorofila observouse que a cada $0,1 \%$ de aumento na concentração de silicato de potássio, houve um incremento de $1,49 \mu \mathrm{g} \mathrm{cm}^{-3}$ no teor de clorofila $b$. Esse acréscimo foi superior ao observado para os teores clorofila $a$.

Os valores de clorofila $b$ variaram entre $19,99 \mu \mathrm{g} \mathrm{cm}^{-3}$, na concentração de $0,1 \%$ de silicato de potássio e $25,65 \mu \mathrm{g} \mathrm{cm}^{-3}$, na dose máxima de silicato de potássio. Quando se comparam esses valores eles mostram uma diferença de $28 \%$ no teor de clorofila $b$ nas folhas do tomateiro.

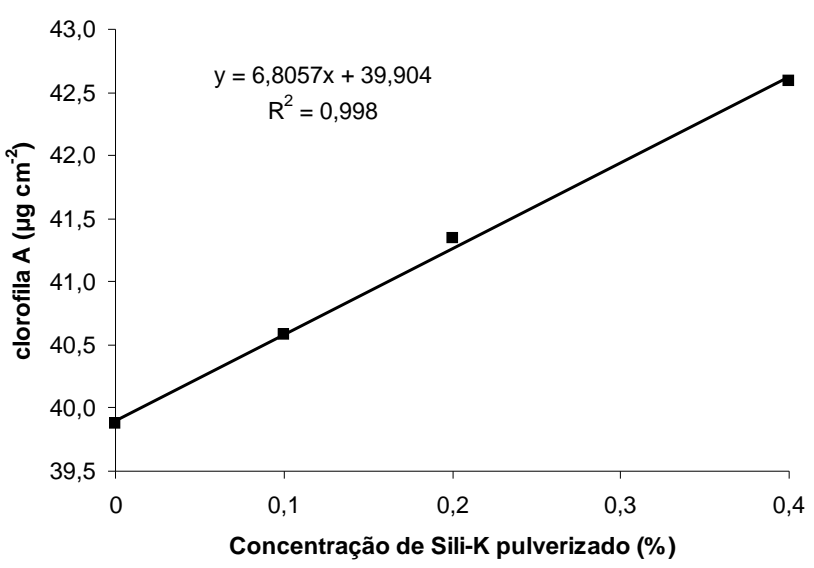

Figura 1 - Teores de clorofila $a$ em folhas de tomateiros cultivados no substrato 1, com a aplicação foliar de quatro concentrações de silicato de potássio. 
Juntamente com o incremento dos teores de clorofila $a$ e $b$, foi também verificado aumento no teor de clorofila total das plantas (Figura 3), o que representa o somatório dos teores de clorofila $a$ e $b$.

A clorofila total aumentou com incremento nas doses de silicato de potássio. Para um aumento de 0,1 unidade na concentração de silicato de potássio ocorre uma elevação de $2,1086 \mu \mathrm{g} \mathrm{cm}^{-3}$ nos teores de clorofila total das folhas do tomateiro.

Os valores de clorofila total variaram entre $60,67 \mu \mathrm{g} \mathrm{cm}^{-3}$ na dose mínima de silicato de potássio a $68,31 \mu \mathrm{g} \mathrm{cm}^{-3}$ na dose máxima, mostrando uma diferença de $13 \%$, quando comparados.

A relação entre os teores dos dois tipos de clorofila apresentou decréscimo com o aumento da concentração das doses de silicato de potássio aplicadas. Ocorreu uma diminuição de 0,09057 na relação entre as clorofilas $a$ e $b$ para cada 0,1 unidade de aumento na concentração de silicato de potássio. Isso ocorreu porque, o teor de clorofila $b$ apresentou um aumento diretamente proporcional às doses de silicato de potássio, em comparação ao verificado para o teor de clorofila $a$.

O aumento superior do teor de clorofila $b$ pode ter sido causado por um crescimento da proporção do complexo coletor clorofila a/b-proteína, em relação ao complexo P-700-clorofila-a-proteína. Um outro fator importante pode ser o maior desenvolvimento de "grana" em cloroplastos, local onde se encontra o complexo a/b-proteína (Mebrahtu \& Havolver, 1991). De alguma maneira, as doses crescentes de silicato de potássio possivelmente estimularam o aumento do teor de clorofila $b$ (Figura 4).

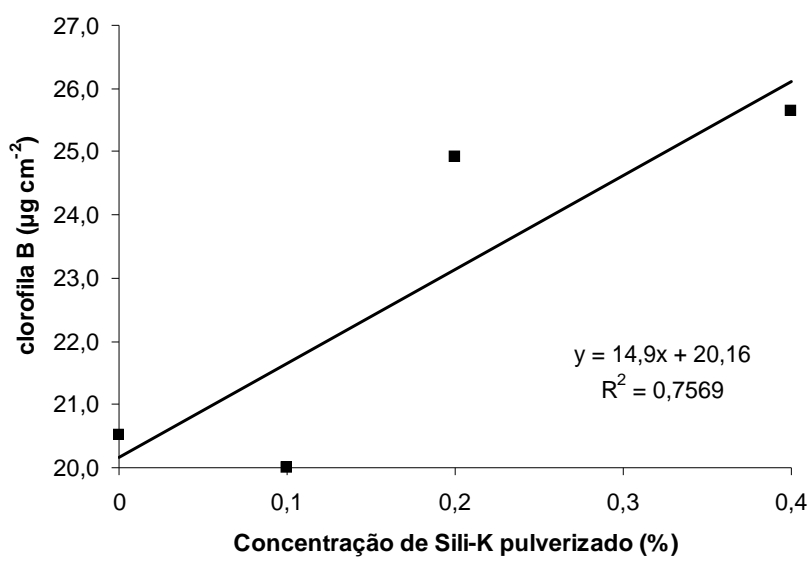

Figura 2 - Teores de clorofila $b$ em folhas de tomateiros cultivados no substrato 1, com a aplicação foliar de quatro concentrações de silicato de potássio.

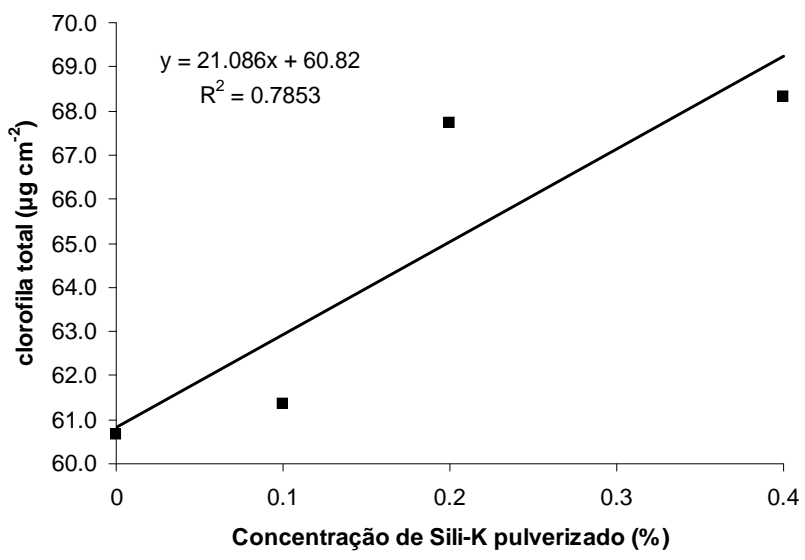

Figura 3 - Teores de clorofila total em folhas de tomateiros cultivados no substrato 1, com a aplicação foliar de quatro concentrações de silicato de potássio. 


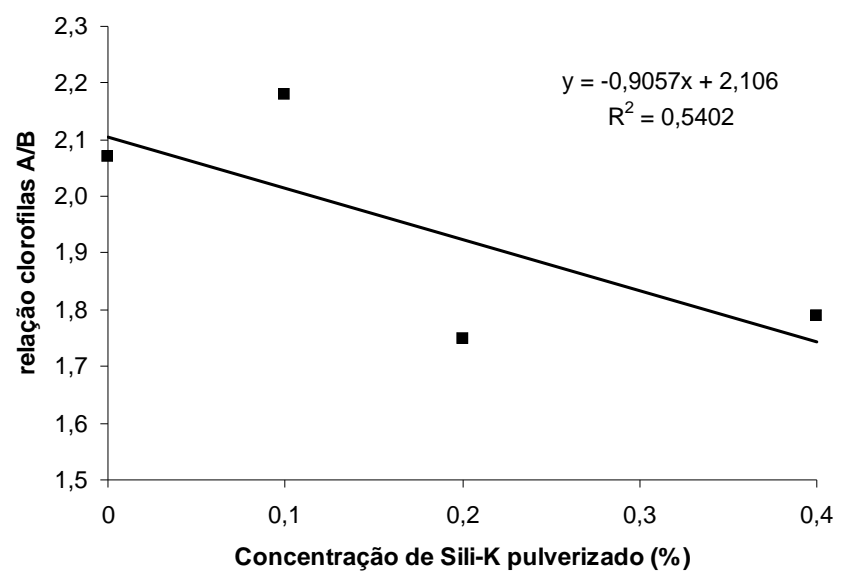

Figura 4 - Relação de teores entre clorofila $a$ e $b$ em folhas de tomateiros cultivados no substrato 1 e pulverizados com quatro concentrações de silicato de potássio.

A clorofila $b$ é considerada um pigmento acessório que auxilia na absorção de luz e na transferência de energia radiante para os centros de reação que estão localizados sobre as membranas tilacóides (Taiz \& Zieger, 2004). Existem dois centros de reação, um deles absorvendo em $680 \mathrm{~nm}$ e outro em $700 \mathrm{~nm}$, os quais interagem entre si por meio de transportadores de elétrons. É a partir da molécula de clorofila, a qual absorve em $680 \mathrm{~nm}$ no espectro visível, que os elétrons oriundos da água são transferidos para a cadeia transportadora de elétrons da fotossíntese (Kluge, 2004). Dessa forma, pode-se inferir que as plantas vão aproveitar melhor a radiação fotossinteticamente ativa que está compreendida entre 390 e $760 \mathrm{~nm}$, o que influencia o crescimento, desenvolvimento e, consequentemente, a produtividade do tomateiro.

Os valores da relação entre as clorofilas $a$ e $b$ variaram de 1,75 na dose de $0,2 \%$ de silicato de potássio a 2,18 na dose de $0,1 \%$. De acordo com (Elbe, 2000), as clorofilas $a$ e $b$ encontram-se na natureza numa proporção de $3: 1$.

Os resultados obtidos de clorofila $a, b$ e total mostraram respostas lineares à aplicação de silicato de potássio. Portanto, são necessários estudos posteriores com doses mais elevadas de silicato de potássio, de forma que seja possível estabelecer um ponto limítrofe para o incremento nos teores de clorofila $a$ e $b$, as quais poderão contribuir de forma significativa na produção de frutos, já que a produção de fotoassimilados deverá ser superior.

A massa média dos frutos da classe $2(60$ a $65 \mathrm{~mm}$ de diâmetro), com a utilização do substrato composto por fibra de coco e casca de café carbonizada, apresentou um ajuste no modelo quadrático, ocorrendo uma aumento até a dose de $0,2 \%$ de silicato de potássio, onde foi observada a maior massa média dos frutos que foi igual a 142,8 t/ha. Já, o menor valor de massa média dos frutos ocorreu sem aplicação de silicato de potássio e foi igual a $121 \mathrm{t} / \mathrm{ha}$.

Carrijo et al. (2004) observaram que a maior massa média de frutos nos cultivos com fibra de coco verde associada à casca de arroz carbonizada, pode estar relacionada à maior capacidade de disponibilização de nutrientes a serem translocados aos frutos.

A maior concentração $(0,4 \%)$ foi menos efetiva que a dose $0,2 \%$ de silicato de potássio. Na concentração de $0,2 \%$ de silicato de potássio, a massa média de frutos da classe 2 foi superior em 18, 14 e 14\% em relação as doses de $0 ; 0,1$ e $0,4 \%$ de silicato de potássio, respectivamente.

O potássio tem grande importância para o tomateiro, porque além de aumentar a produção tem efeitos benéficos sobre a qualidade comercial dos frutos (Alvarenga, 2004).

\section{CONCLUSÕES}

O aumento das doses de silicato de potássio estimula, de forma linear, a concentração de clorofila $a$, clorofila $b$ e clorofila total em folhas de tomateiros.

A relação entre clorofila $a$ e clorofila $b$ em folhas de tomateiros apresenta decréscimo com a aplicação de doses de silicato de potássio mais elevadas.

A dose de $0,2 \%$ de silicato de potássio mediante pulverizações foliares, no substrato composto por $2 / 3 \mathrm{de}$ fibra de coco e 1/3 de casca de café carbonizada, foi capaz de gerar ganhos significativos apenas para a massa média de frutos da classe 2 . 


\section{REFERÊNCIAS BIBLIOGRÁFICAS}

ALVARENGA, M.A.R. Tomate: produção em campo, em casa-de-vegetação e em hidroponia. Lavras: UFLA, 2004. 400p.

ARAÚJO, W.B.M. de; ALENCAR, R.D.; MENDONÇA, V.; MEDEIROS, E.V. de; ANDRADE, R. de C.; ARAÚJO, R.R. de. Esterco caprino na composição de substratos para formação de mudas de mamoeiro. Ciência e Agrotecnologia, Lavras, v.34, n.1, p.68-73, jan./fev., 2010.

BLACKBURN, G.A. Hyperspectral remote sensing of plant pigments. Journal of Experimental Botany, v.58, n.4, p.855-867, 2007.

CARRIJO, O.A.; VIDAL, M.C.; NEVILLE, V.B. dos; SOUZA, R.B. de; MAKISHIMA, N. Tomato cropp production under different substrates and greehouse models. Horticultura Brasileira, Brasília, v.22, n.1, p.5-9, jan./jul. 2004.

CASTELLANE, P.D.; ARAÚJO, J.A.C. Cultivo sem solohidroponia. Jaboticabal: FUNEP, 1995. 43p.

CAVINS, T.J.Adaptation of the pourthru nutrient extraction procedures to greenhouse crop production. Raleigh: Faculty of North Caroline State University, 2002. 148p.

ELBE, J.H. von. Colorantes. In: FENNEMA, O.W. Química de los alimentos. 2.ed. Zaragoza: Wisconsin, 2000. p.782-799.

EPSTEIN, E. The anomaly of silicon in plant biology. Proceedigns of the National Academy of Sciences of the United States of America, Washington, v.91, n.1, p.11-17, Jan. 1994.

EPSTEIN, E.; BLOMM, A.J. Nutrição mineral de plantas: princípios e perspectivas. 2.ed. Londrina: Planta, 2006. 403p.

FIGUEIREDO, F.C.; BOTREL, P.P.; TEIXERA, C.P.; PETRAZZINI, L.L.; LOCARNO, M.; CARVALHO, J.G. de. Pulverização foliar e fertirrigação com silício nos atributos físico-químicos de qualidade e índices de coloração do morango. Ciência e Agrotecnologia, Lavras, v.34, n.5, p.1306-1311, set./out., 2010.
GONÇALVES, M.V.; LUZ, J.M.Q.; RODRIGUES, C.R.; QUEIROZ, A.A. Produtividade de batata cv. Atlantic sob diferentes doses de silicato de potássio via foliar. Horticultura Brasileira, Brasília, v.26, n.2, p.S694-S698, jul./ago. 2008.

KLUGE, R.A. LCB - 311, Fisiologia vegetal: apontamentos de aulas teóricas de fotossíntese. Disponível em: <ihttp://orion.cpa.unicamp. br/sbfv iarquivos/aulas/gradol/06fotoguímicadafotossintese 'fotossínteseKluges. Acesso em: 22 mar. 2004.

KORNDORFER, G.H. Elementos benéficos. In: FERNANDES, M.S. (Ed.). Nutrição mineral de plantas. Viçosa, MG: Sociedade Brasileira de Ciência do Solo, 2006. p.356-374.

MARSCHNER, H. Mineral nutrition of higher plants. 2.ed. London: Academic, 1995. 889p.

MEBRAHTU, T.; HAVOVER, J.W. Leaf age effects on photosynthesis and stomatal conductance of black locust seedlings. Photosynthetica, Prague, v.25, n.4, p.537-544, 1991.

RICK, C.M. The potencial of exotic germplasm for tomato improvement. In: VASIL, I.K.; SCOWCROT, W.R.; FREY, H.J. (Eds.). Plant improvement and somatic cell genetics. New York: Academic, 1982. p.478-495.

SÁNCHES, F.P. Propriedades y características de los substratos: turba y fibra de coco. In: FERNÁNDEZ, M.F.; GÓMEZ, I.M.C. (Eds.). Cultivo sin suelo II. Almería: FIAPA, 1999. p.65-92.

SCHUCH, W.; KANCZLEER, J.; ROBERTSON, D.; HOBSON, G.; TUCKER, G.; GRIERSON, D.; BRIGHT, S.; BIRD, C. Fruit quality characteristics of transgenic tomato fruit with altered polygalacturonase activity. HortScience, Alexandria, v.26, n.12, p.1517-1520, Dec. 1991.

STREIT, M.N. et al. As clorofilas. Ciência Rural, Santa Maria, v.35, n.3, p.748-755, 2005.

TAIZ, L.; ZIEGLER, E. Fisiologia vegetal. 3.ed. Porto Alegre: Artmed, 2004. 693p. 